\title{
DISTURBANCES IN VERNACULAR ARCHITECTURE OF TOGO'S RURAL SETTLEMENTS
}

\author{
Y. Hernández Navarro ${ }^{1, *}$, P. de Dato ${ }^{1}$, A. Langa Lahoz ${ }^{1}$ \\ ${ }^{1}$ Universitat Politècnica de València, Valencia, Spain - (yoherna, pasdeda)@upv.es, alangalahoz@gmail.com
}

Commission II - WG II/8

KEY WORDS: Togo, Earthen Architecture, Rural Settlement, Imported Building Materials, Cultural Risks, Sustainable Development

\begin{abstract}
:
According to the United Nations (UN) Africa accounts for only 13\% of the world's urban population and less than half of the inhabitants of this continent (43\%) live in urban areas (Xinhua News Agency, 2017). Therefore, the cultural importance of rural architecture in this context is remarkable both locally for each society and generally for human knowledge. As Paul Oliver pointed out, vernacular architecture is the architectural language of people with their ethnic, regional and local dialects (Oliver, 1997), and it should be considered a treasure containing the knowledge, development and progress of a civilization. The formal and material results of this development lead to the reopening of the debate on its sustainability and its effects on human behaviour. The structural changes of rural habitats are putting the preservation of their cultural heritage at serious risk. The current demand for habitability fosters the use of imported materials such as cement and sheet metal to replace earthen walls and straw roofing in the simple constructions, solutions that deceptively improve the comfort of the inhabited spaces. The present article analyses residential construction typologies of traditional rural settlements of Togo, where the constructive, formal and technical variety is replaced by general solutions that, without achieving the desired housing improvement, are nonetheless contributing to the social detachment from traditions that represent the cultural identity of each community. The methodology aims at the identification and characterization of traditional residential typologies, and a final consideration evaluates the balance between sustainable development and the conservation of cultural values in rural settlements.
\end{abstract}

\section{INTRODUCTION}

\subsection{Togo. Approach to the context}

Togo is a sub-Saharan country on the Gulf of Guinea between Ghana and Benin. With its limited coastline of $56 \mathrm{~km}$ it stretches $550 \mathrm{~km}$ north to the border with Burkina Faso, widening in its middle to $110 \mathrm{~km}$. Its area of $56785 \mathrm{~km}^{2}$ makes it one of the smallest countries on the African continent and its size is comparable to that of Croatia (Central Intelligence Agency USA, 2007) (nationsonline.org, 2007).

The urban population represents less than half $(42.8 \%)$ of the total population of $8,263,064$ people, , and that explains why there aren't many overly large cities. In fact, the urban population is concentrated in only 20 cities, only 4 of which have more than 100,000 inhabitants, including the capital Lomé, which concentrates more than 500,000 , while the rest compute between 10,000 and 100,000 people (Figure 1) (World Population Review, 2016). Therefore, Togo can be considered an eminently rural country, as the following factors show:

Economy: The fundamentally agrarian, commercial and subsistence economy of Togo concentrates $65 \%$ of the workforce in agriculture, fishing and forestry, leaving 5\% to activities related to mining, manufacturing, energy production and construction and $30 \%$ to the employment in the service industry related to government activities, communications, transport, finance and all economic activities that do not produce material goods (Central Intelligence Agency USA, 2007).
National transport system: The main inland communication route is a highway that crosses the country from North to South, connecting the most urbanized and wealthy cities and towns. Therefore, the settlements which are located further away from this road, understandably assume a greater degree of isolation emphasizing their rural character.

Social structure: Rurality is the still visible trace in the fundamental character of traditional African societies, and it is preserved and protected for cultural reasons. The Togolese social structure originates from the family and extends to the clan, that is, to groups of families with a common ancestor, and farther to the ethnic group. There is a system of laws with rights and obligations on all levels. It is transmitted and preserved orally and promotes the prosperity of the group instead of individual interests. The awareness of belonging to a group has strengthened the feeling of attachment and identity to a specific culture, ensuring its conservation and transmission from generation to generation (Mballa, 2011).

This cultural balance was struck by two historical events which further demonstrated the sense of belonging to a social group. The first of these events is slavery. Starting in the 16th century until the 18th century, Togo and the surrounding area was known as "the Slave Coast" as it became a trading centre for Europeans, raising a feeling of rejection towards anything considered foreign.

The second event was the succession of three colonising occupations suffered by the Germans between 1884 and 1913,

\footnotetext{
* Corresponding author
} 
by the English between 1913 and 1919, and by the French between 1919 and 1960, who tried to organize the territory emulating the western model wihtout taking into account its distance from African traditions. The predictable result drew further attention to the importance of the cultural character of traditional Togolese society. The territorial transformation from ethnic states to proto-states was not accompanied by a change in mentality causing a rupture between state and town. Imported proto-states imposed borders dividing ethnic groups and attempted to officialise the use of colonial languages, thus fostering a society with no sense of cultural belonging (Fuentes Castaños-Mollor, 2017).

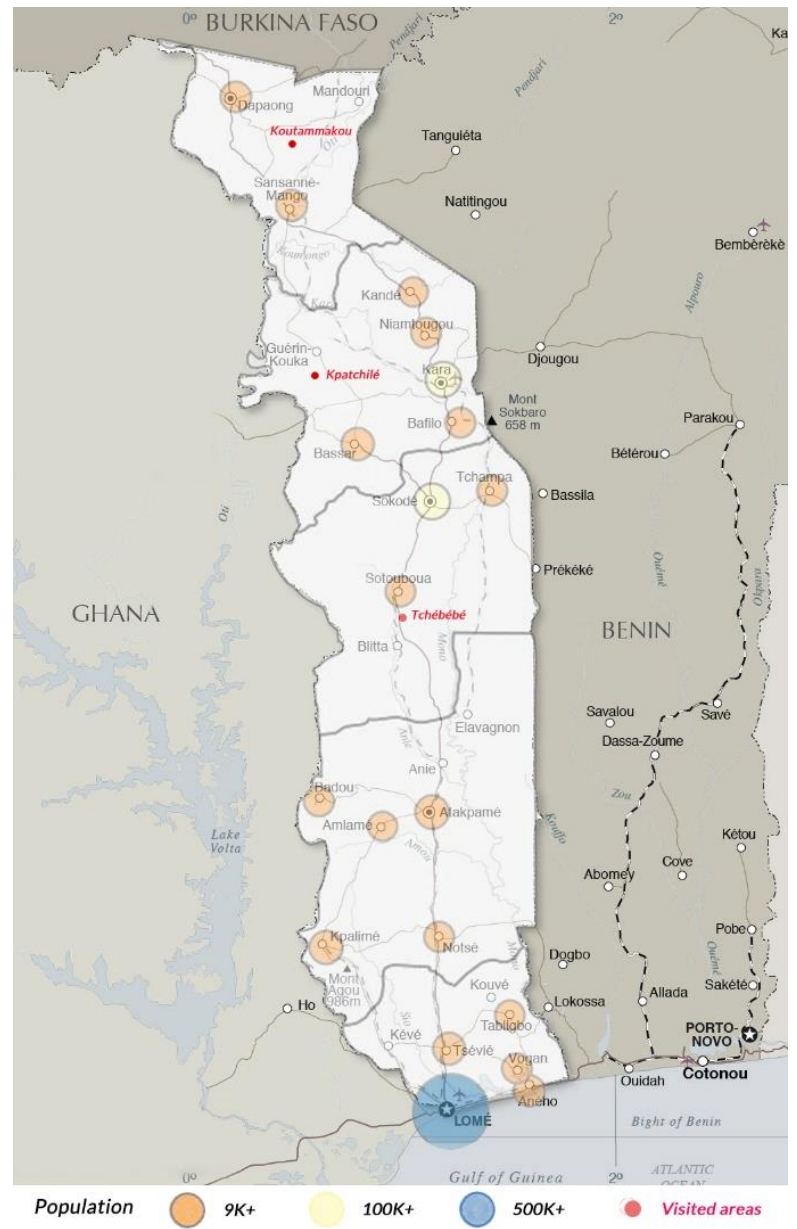

Figure 1.Urban areas and visited rural áreas.

Currently "there are around 40 ethnic groups in Togo. The largest is the Ewe in the south, who account for $32 \%$ of the population, other ethnic groups include the Kotokoli (Tem) and the Tchamba in the center of the country and the Kabye in the northern region $(22 \%)$. The Ouatchis account for $14 \%$ of the population. While the Ewe and Ouatchi are often considered the same group, the French, who studied both, consider them separate people. Other smaller ethnic groups include the Mina, Mossi and Aja. The European population makes up less than $1 \%$ of Togo's population." (World Populationa Review, 2016) (Figure 2).

\subsection{Sustainable development at risk}

There is global consensus on the consideration of sustainable development as a guiding principle for achieving global development. The UN defined this concept in 1987 as "Meeting the needs of the present generation without compromising the capacity of future generations" (Sung, 2011) and argued that sustainable development could only be achieved if we worked integrally in three areas: economic, social and environmental. Convergence between economic development, social improvements and protection of the environment is therefore necessary. In 2010, the progress made in the 3 areas was assessed.

Despite the economic acceleration of developed and emerging countries since the mid-1990s, in terms of economic development the per capita income of sub-Saharan African countries decreased in comparison to other regions. Global economic development has not been achieved and it will be necessary to multiply incomes by 20 or more to achieve adequate human development in poor regions such as those in Sub-Saharan Africa, but this will take more than a generation (Zukang, 2010).

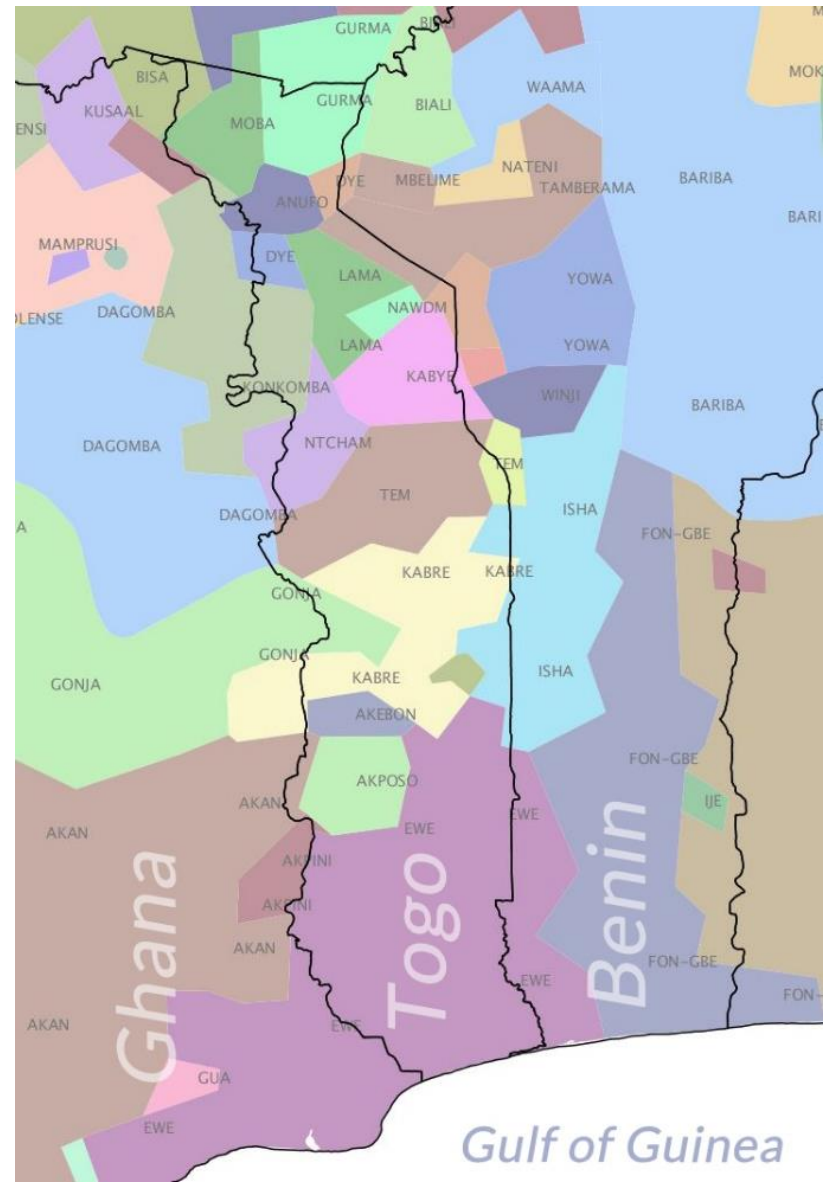

Figure 2. Map of ethnic diversity. (Own elaboration from Worl Map Harward Education, 2001)

As far as social development is concerned, a large disparity between countries remains. Sub-Saharan Africa shows a slow progress, no progress at all or even a worsening (Zukang, 2010). Reducing poverty remains a pending goal, and overcoming it requires the principle of solidarity and cooperation among countries with higher levels of development. Safe water supply, sanitation infrastructure and access to decent housing are recognized as basic needs not yet achieved.

As for environmental development, the climate change due to greenhouse gas emissions from more developed countries is recognised to producehighly negative consequences in poor 
countries and especially in vulnerable areas such as rural environment. Moreover, local environmental problems such as waste management, especially of imported materials like plastic or metal, must be added to this concern.

In 2015, the UN approved the Sustainable Development Goals (SDGs) within the framework of the 2030 Agenda. These are 17 goals related to different areas in order to improve the future, stretching from climate change to economic inequality, innovation, sustainable consumption, peace and justice. SDGs are integrated objectives, that is, they are interrelated and progress in one of them will have a positive impact on others (Gil Legaz, 2015).

In the course of this research, we could observe how the socalled development of the rural settlements of Togo affects the field of decent housing. 3 human settlements with a different urbanization status have been visited: Kara (the second most important city in the country, with more than 100,000 inhabitants and highly urbanized), Tchébébé (located $140 \mathrm{~km}$ south of Kara, on the N1 national route, with less than 90,000 inhabitants and an incipient urbanization) and Kpatchilé and its 7 villages (located $100 \mathrm{~km}$ west of Kara and only $30 \mathrm{~km}$ from the border with Ghana in a rural environment).

During the stay, it was possible to observe the general desire to improve self-built houses, leading the population to use imported materials to replace traditional materials but following the same traditional construction techniques. Although these materials need less maintenance, they are causing formal and constructive transformations with a strong impact on aesthetic aspects, thus resulting in new shapes which are alien to the cultural identity of the place. Moreover, the habitability of the interior spaces worsens, producing other harmful effects.

This circumstance has negative consequences in all the areas of sustainable development: from an environmental point of view, the use of sheet metal roofs or cement blocks prevents an unharmful integration into the ecosystem, increasing waste and pollution and damaging health by generating insalubrious spaces; from a social ponit of view, the elimination of traditional materials in construction processes leads to the loss of knowledge related to local culture and disrupts territorial identity; finally, from an economic point of view, it discourages autonomy and self-sufficiency to the disadvantage of local activities.

\section{OBJECTIVE AND METHODOLOGY}

This research is carried out within the framework of the International Cooperation actions run by the religious order of the Marianist Sisters of Togo.

Although the study is much broader, this article focuses onvernacular construction typologies linked to the residential use of rural settlements. The purpose is to identify the material alterations caused by unsustainable development and to reflect on the effect of material disturbances on cultural identity.

The work method used is structured in 3 phases:

- Phase 1: Previous studies. A bibliographic review of the historic, economic and social context of Togo as well as a theoretical review of development cooperation and of the objectives of sustainable development wew carried out in order to anticipate and identify relevant data that were to be studied on site.
- Phase 2: Data collection. A 90-day stay was divided between areas with a very different environment. We spent the first 50 days in Kara, which has a marked urban character. During this time, we studied construction techniques in urbanized environment, working together with technicians and construction workers. Then we stayed another 40 days in Tchébébé and Kpatchilé, both in rural environment. This experience was accompanied by visits to different villages in the Koutammakou prefecture, in the north-eastern area of Togo close to the Benin border. This region has been recognized as a World Heritage Site by Unesco since 2004 (United Nations Educational, 2004). HHhouses and customs of the local Batammariba people have been studied firsthand. During this phase we collected quantitative and qualitative data.

As a result, the quantitative data include metric annotations and photographs of the different types of buildings, construction techniques and materials used, while the qualitative data were gathered in conversations with different population profiles (students between 11 and 18, fathers and mothers of families and Togolese clergy from the Marianist community in the country).

- Phase 3: Digital processing of the information collecte during phase 2 . The analysis of the collected data aimed at identifying and cataloguing the most common traditional building typologies, as well as their characteristics, degradations and pathologies. The sketches made on site were redrawn to highlight the functional organization of settlements, the formal aspects of buildings and construction techniques.

\section{RESIDENTIAL ARCHITECTURE IN RURAL SETTLEMENTS OF TOGO}

The current rural settlements show the evolution of the natural and spontaneous growth of families. This development follows the same laws of change as the families themselves, but with the incorporation of new materials such as sheet metal and cement. This fact was already explained by Babar Muntaz in the 1970s. He seriously doubted that the new architecture would eventually maintain the social and geographical harmony that was innate in indigenous constructions (Mumtaz, 1978).

\section{1 "Tata" or "Takienta"}

The traditional houses of the Batammariba are called "tata" or "takienta". You can find them in the Koutammakou prefecture and all the way to Benin through the mountains and plains of Atakora. The general composition of the house comes from the aggregation of circular basic units generating more complex sets closed to the outside.

These groups can be one or two-storey houses. In the first case, the union between basic units forms a turret by means of a wall, thus creating an interior patio where the family spends a lot of time. In the second case, the perimeter wall grows between 3 and 4 meters high and delimits a roof terrace from which small turrets with conical roofs stand out. The entire construction recalls the shape of small castles (Figure 3 ).

According to Yavo, 6 general types of two-storey houses have been identified amongst the Batammariba in Togo and Benin: Bèrba, Béyanbé, Osori, Otammari, Otchiaou and Tabaya. Slight formal variations can be identified between clans or families (Yavo, 2013). 


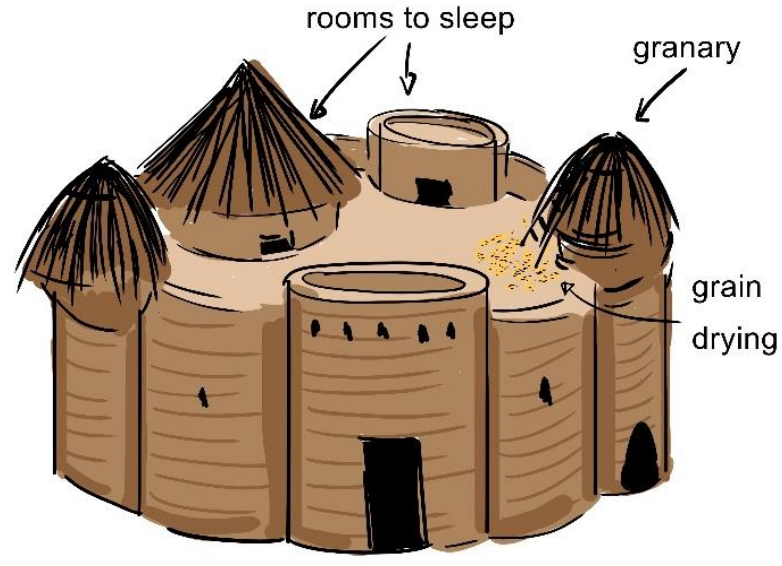

Figure 3. Sketch of vernacular two-storey house.

A snake devouring its tail

Infinity principle

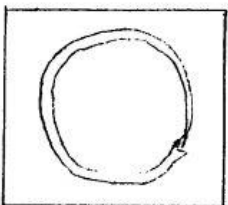

$\sharp$

The room

Unit of infinity principle
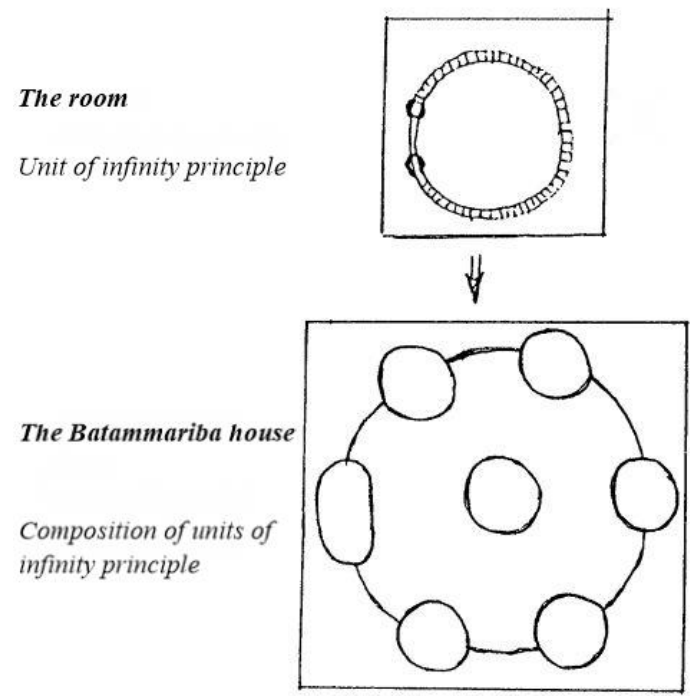

Figure 4. Batammariba architectural concepts as inspired by the circular form (Yavo, 2013).

Morphological analysis: Regardless of their functional type, buildings are based on a circular form, due to the importance of the circle in traditional African culture. Infact, the Batammariba society believes in eternal life and the circle symbolizes perpetuity and stability being the expression of immortality and the Divine. Accordingly, identity aspects such as dances of spiritual connection follow the shape of a circle, formed by sitting men and women who avoid second rows to be all interrelated with each other. They even drink and eat from circular utensils passed on from one to the other following the circle (Yavo, 2013).

Hence, the shape of the basic housing unit symbolizes a snake that devours its tail, representing the idea of infinity. The
Batammariba house is created through the addition of circular units connected by walls and defining a global circular shape (Figure 4). These formal aspects are supported by the observation of nature. Primitive tribes took example from the baobab tree with its large hollowed-out trunk and thick bark. Its shape could provide protection and shelter, as well as a cooler interior environment thanks to few and small openings. Moreover, these holes would allow them to see what is happening outside without being seen. The formal aspect of the Batammariba houses is therefore also related to the shape of the baobab.

Functional analysis: Batammariba families spend most of the day outdoors, in the patio or outside. So, the construction is designed to meet the family's fundamental needs of shelter at night and custody of their most precious assets, livestock and grain from the crops. Access is gained through a small room where the grain is prepared for cooking. The hen house is also located in this room to shelter the hens at night. On the ground floor the animals sleep (goats or dogs, generally) while the father of the family watches over the house. On the upper floor, which is accessed through stairs made from a tree trunk, the small turrets that protrude from the roof terraces serve as sleeping rooms or grain store, although the function of the spaces may change according to communities (see (Yavo, 2013)). The remaining area of the roof-terrace is used to spread out and dry the grain of the crops.

Constructive and material analysis: The most common materials are earth for the walls and the covering of the roof terraces and straw for the conical thatch roofs. The basic element of the wall construction is the tabodi, which is a mud ball, basically formed with earth and water, to which straw and dung are sometimes added and which is molded by hand. The construction process consists of adding one row of tabodi, the height of which is between 5 and $10 \mathrm{~cm}$ in the plastic state, on the previous, giving the wall a slightly trapezoidal shape to increase its stability.

The covers can be a flat mud roof of or a conical straw roof. The flat roofs are supported by forked poles supporting beams and distanced 15 to $30 \mathrm{~cm}$ one from the other. On this layer there is another layer with branches placed at right angles. Subsequently, layers of mud are spread out, while dung is added to the mixture in the last layer in order to make the surface waterproof (Figure 5).

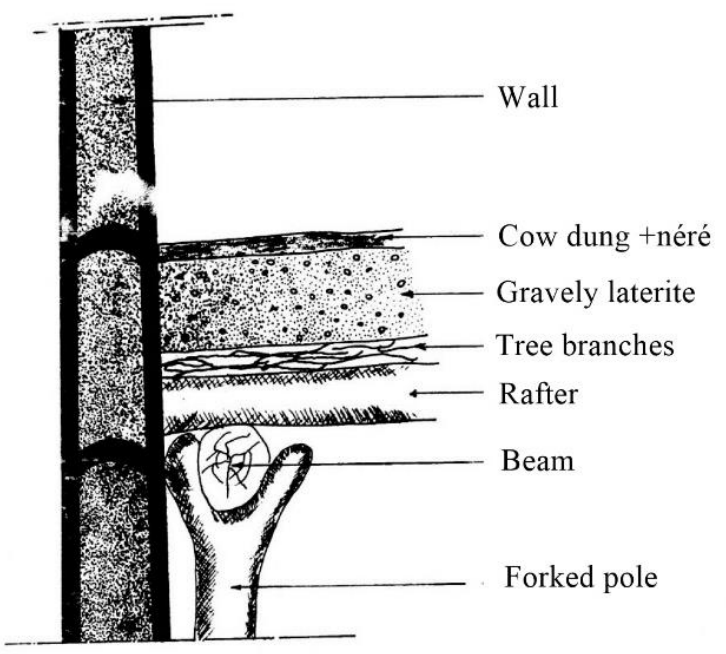

Figure 5. Detail of the flat roofing system (Yavo, 2013). 
Thatch roofs are used in small huts and they are built starting from a structural base of palm stalks: the thickest end rests on the wall and the thinnest end is tied to the upper apex with a rope. To secure this system, every 20-30 centimeters these posts are linked to each other crosswise with bands of corn stalk. The final layer of straw is laid out and tablecloths of braided straw, previously tied with ropes, are arranged spirally in ascending order. Occasionally, braided straw mats are added below this layer to increase the non-permeability of the cover.

\subsection{Rural dwellings}

At a certain distance from these unchanged environments are rural settlements that concentrate a greater number of inhabitants, such as Kpatchilé and Tchébébé, where a series of formal, functional and material changes can be observed.

Morphological analysis: The arrangement of the residential units continues to be centralized. But the perimeter walls that unite and limit the property are dematerialized by taking the form of a palisade or by adding more or less thick mats of braided straw or other materials, thus contributing to the loss of perception of the infinity principle. So the housing loses its initial unity and is understood as a scattered set of basic units.

Furthermore, the geometry of the basic units is modified. Although they maintain circular shapes for spaces such as the apatan (family gathering place), the kitchen and the barn, the sleeping rooms are formalized by means of rectangular parallelepipeds to increase their number, mirroring the family growth (Figure 6).

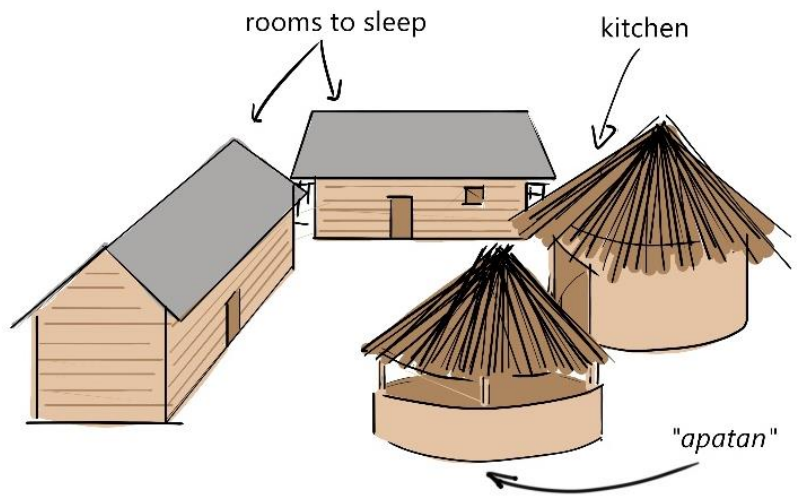

Figure 6. Sketch of adobe house with material disturbances.

Functional analysis: Families preserve their primitive lifestyle outdoors, where they spend most of the day, using the few shadows of the existing trees to gather. Therefore, they reduce the built units to the minimum requirement. Generally, rural dwellings are composed of a kitchen that serves more as a storage for utensils than as a proper cooking place, the apatan used as a meeting place and for eating in unfavourable weather conditions, one or two sleeping rooms (organized in one or two spaces) and the barn.

Apatan and kitchen present the same type of building, but the kitchen is more common: on the contrary, the apatan, appears as a sign of prosperity in families with more resources.

Another but not general cultural change can be observed in the sleeping rooms, which are no longer separated by gender but by generations, expanding the number of buildings as the clan grows.
Constructive and material analysis: Besides the traditional materials such as earth and straw, the use of sheet metal for roofs and of cement blocks in walls has begun to spread.

The construction process of the thatched roofs maintains the primitive techniques, but its replacement by sheet metal is considered appropriate on two occasions. Firstly, after the torrential rainy season, if the damage of the thatched roof is important, the straw is replaced by sheet metal, and secondly, when the family expansion suggests a new construction, opting again for sheet metal.

The construction process of the walls is different instead because the basic element of wall construction is adobe and requires greater work skills. For this reason, families request the help of a master mason to carry out the construction and preparation of the material.

Besides, this technique is used less often than the cement block wall, especially when building new parts of the house. As a result, in rural environments both local and imported materials coexist disharmoniously. Because of the better means of communication in towns, the presence of the imported materials there is remarkable.

Despite the "innovative" use of materials, they are employed in a traditional way, worsening the quality and comfort of the spaces. On the one side, the thermal inertia of the adobe walls is diminished when it is replaced by cement block walls generating warmer and more humid interior spaces. On the other side, the sheet metal cover, in place of the straw layer directly supported by the structure of branches, causes condensation and originates, among other damages, the oxidation of the material, transforming the interior spaces into real human cookers (Figure 7).

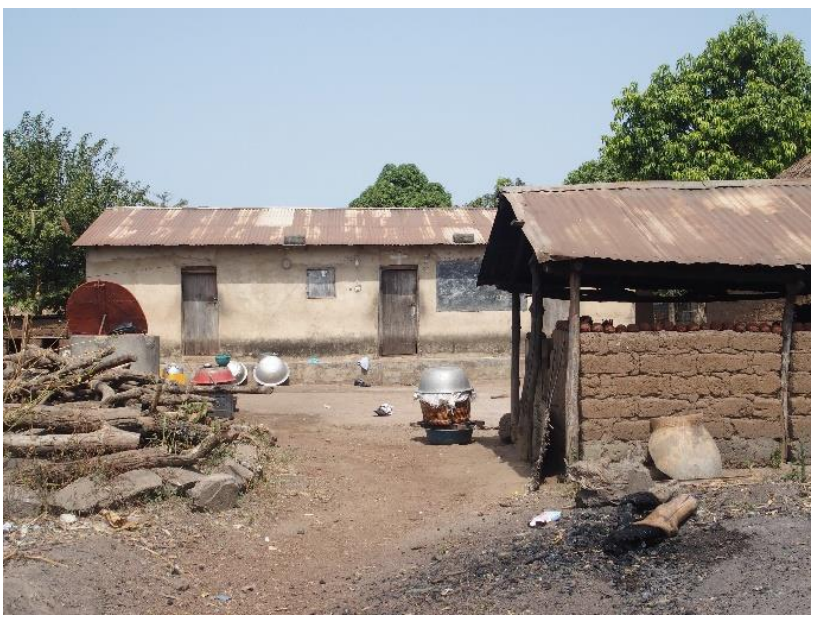

Figure 7. Renovated kitchen and sleeping rooms. Formal consequences arising from the use of imported materials.

\section{CONCLUSIONS}

In the traditional architecture of Togolese rural settlements forms convey the identity values of its culture. The geometric concept of the circle has a spiritual value. Compositional parameters such as arrangement, proportion, symmetryasymmetry and rhythm demonstrate the idea of beauty and the meaning that cosmology and the human body have in this culture. 
Therefore, traditional rural settlements represent tangible documents preserving the cultural values of each social group and providing us with information about their ways of life, their customs and their ideological beliefs.

"While materials do not necessarily determine the form and content of architecture, it is obvious that the form of any art is conditioned, to a greater or lesser degree, by the medium through which it is expressed." (Yavo, 2013). Earth is the most common material in the construction of vertical enclosures because it is an abundant resource and curvilinear forms can be easily modelled from it. The trunks and branches of trees, as well as the roofing thatch adapt smoothly to curvilinear geometries, contributing to harmony of the ensemble.

When "innovative" materials such as sheet metal are introduced, do they influence the shapes? Obviously, they do. The directionality of the metal sheets facilitates its adaptation to orthogonal rather than circular spaces. For example, the apatan is originally circular in shape but in case of reconstruction it is covered with sheet metal. The introduction of this new material causes a change in its shape, adapting it to regular polygons. The same situation happens with the other basic units of the house when introducing this material (Figure 8). Moreover, the incorporation of "innovative" materials causes other pathologies in the traditional structure which did not exist before Differential movements between materials with very different physical behavior (metal-mud) become obvious due to damages such as cracks in healthy walls which facilitate the infiltration of water into the wall structure, thus accelerating its degradation.

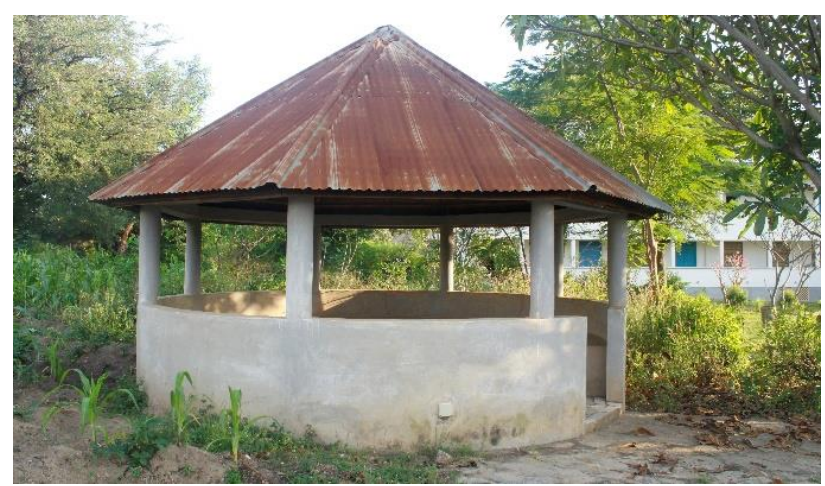

Figure 8. Renovated apatan. Formal consequences arising from the use of imported materials.

In the 1970s Babar Muntaz already signalled the proliferation of "innovative" materials incorporated into traditional African constructions discussing their integration and social, environmental and economic harmony. After 50 years, the situation is aggravated by the extension of rusty metal roofs with their corresponding unhealthy interior spaces, which make the survival of some already vulnerable social groups even more arduous.

These communities incorporate solutions imported from other cultures and consider them better than their own, identifying them as signs of the desired progress. Naturally, this causes a feeling of detachment from their customs and leads to forgetting their identity values.

Therefore, the questions are: Is the progress of societies with a low economic development possible while preserving their cultural heritage? Or is the economic progress necessarily linked to the acceptance of globalized solutions that in turn generate rejection of the cultural identity of each community?
Within another 50 years, evidence will surely answer these questions. By then, the so-called global sustainable development will be hopefully achieved, and in the architectural field, due to its impact on cultural identity, the sustainable development may become true.

\section{REFERENCES}

Central Intelligence Agency USA, 2007. The World Factbook. https://www.cia.gov/library/publications/the-worldfactbook/geos/to.html (Accessed: 10 January 2020)

Fuentes Castaños-Mollor, B., 2017. Policy study on precarious human settlements in sub-Saharan Africa. Case study: Ghana, Kenya and South Africa. Comillas Pontifical University.

Gil Legaz, M.C., 2015. Sustainable Development Goals. https://www.un.org/sustainabledevelopment/en/ (Accessed: 15 January 2020)

Mballa, L.V., 2011. The family and the clan in Africa: a prelude to the socialization of the African. https://aprenderly.com/doc/3419630/la-familia-y-el-clan-enafrica--antesala-de-socialización (Accessed: 15 December 2019)

Mumtaz, B., 1978. Aldeas en el Volta Negro. In Cobijo y sociedad (1a Edición, pp. 89-100) P. Oliver (Ed.). H. Blume Ediciones.

nationsonline.org, 2007. Nations Online Project. https://www.nationsonline.org/oneworld/map/google_map_togo .htm (Accessed: 23 November 2019)

Oliver, P., 1997. Encyclopedia of vernacular architecture of the world. Cambridge University Press (ed.). Cambridge University Press.

United Nations Educational, S. and CO, 2004. Decisions adopted at the 28th session of the World Heritage Committee.

World Populationa Review, 2016. Population of Cities in Togo (2020). https://worldpopulationreview.com/countries/togopopulation/cities/ (Accessed: 26 December 2019)

Worl Map Harward Education, AfricaMap.http://worldmap.harvard.edu/africamap/

Xinhua News Agency, 2017. ONU: 68\% de población mundial vivirá en zonas urbanas para 2050. http://spanish.xinhuanet.com/2018-05/17/c_137184574.htm (Accessed: 20 January 2020)

Yavo, P., 2013. Technical know-how in the indigenous knowledge system underlying Batammariba Traditional Architecture in Togo and Benin [University of KwaZulu-Natal, Durban]. http://hdl.handle.net/10413/11484 (Accessed: 15 November 2020)

Zukang, S., 2010. Avances logrados hasta el momento y lagunas que aún persisten en la aplicación de los resultados de las principales cumbres en la esfera del desarrollo sostenible y análisis de los temas de la Conferencia. 